\title{
Influential Factors on Analytical Methods in External Audit
}

\author{
Ehsan Khansalar ${ }^{1}$, Mahmoud Lari Dasht-Bayaz ${ }^{2}$ \& Javad Zarei ${ }^{2}$ \\ ${ }^{1}$ Kingston Business School, Kingston University, London, UK \\ ${ }^{2}$ Department of Accounting and Economics, Islamic Azad University, Qaenat Branch, Birjand, Iran \\ Correspondence: Ehsan Khansalar, Kingston Business School, Kingston University, London, UK. E-mail: \\ e.khansalar@kingston.ac.uk
}

Received: August 19, 2015

Accepted: September 28, 2015

Online Published: October 25, 2015

doi:10.5539/ijef.v7n11p76

URL: http://dx.doi.org/10.5539/ijef.v7n11p76

\begin{abstract}
In 1394, a research was conducted to detect the influential factors on using analytical methods in external audit. Results of research hypothesis examination revealed that analytical procedures were used effectively during implementation steps of external audit and needed initial information including industry indices, budget, standard costing, firm size, accounting systems, effective internal controls, audit managers work history and his(her) coworkers, educational level of audit manager and his(her) coworkers, industry, familiarity with statistical-analytical procedures and institution size influence on using analytical procedures. However among factors mentioned above only firm size, accounting systems and effective internal controls are crucial factors which influence on using analytical procedures.
\end{abstract}

Keywords: external audit, analytical procedures, accounting systems, standard

\section{Introduction}

Because of growing complexity and lack of economical activities, financial information is very important in evaluation the personnel and economical units, so reliable financial information is the necessity for survival of modern community. Investors, creditors, government rely on reasonable and logical information which are provided by others. In many cases, information providers goals are in contrast to users goals; so due to this reason, external auditors are necessary (Sheikhesmaeeli et al., 1393).

In modern world that reducing cost and developing efficiency are so important, competition in audit domain has increased worldwide, particularly in modern industrialized countries. This forces auditors to develop the efficiency of their procedures. One of the most important ways to develop the efficiency in audit domain, is using analytical procedure, because these procedures are fast, time saving and need low prices for implementation.

Although there are literature audit standards, papers and books about analytical surveys done by professional communities, lack of uniform analytical ways for evaluation, makes auditors to use methods and standards according to their taste and practices. This factor, lack of knowledge about analytical procedures and usage caused limitation in using them (Rahmaniyan \& Ghasemi, 1392).

According to audit standards, the aim of auditing financial statements is to receive the comment of external auditor about consideration the accounting standards. To achieve this goal, external auditor needs to obtain considerable evidence by means of audit procedures including audit, observation, query, approvals, calculations, sufficient analytical audit procedures (Publication of 124 audit organizations, 1390).

Audit procedures are practical, so auditors use them to obtain information and reliable evidence. Their goal is delivering professional suggestion about financial statements. Because today, fast concluding and cost reduction in audit are crucial factors influencing on audit practice, analytical procedures are considered one of the influential methods on audit practice by auditors (Hassas Yegane, 1376).

Analytical examination of audit, analyses the association between accounts and practices of different kinds of financial statements to ensure their capacity and reasonability. Analytical procedure uses ratios and trends of different types of financial statements. Therefore, auditor tries to find the relations and irregular circumstances, so evaluating item (items) of financial statements is necessary. Because non-financial relations between items of financial statements may be originated from different causes, often different aspects of analytical procedures 
may be implemented (Nikkhah Azad, 1382).

Fundamental application of analytical procedures in audit is the justifiable relation between accounts, financial and practical information. These relations are considered stable until changing the circumstances. For example some particular circumstances may change these relations including businesses and unusual event, changing the accounting method, business-economical change, random oscillations and presenting incorrect data (Samavati, 1379). In this research, we will examine analytical procedures in erchternal audit.

\section{Related Reserch}

Rezaee (1391) in his article "examination the influence of internal audit on external audit process" evaluated the influence of internal audit on external audit. Results of this research revealed that internal auditors can help external auditors. For instance, by influencing on steps 1, 2, 3 of audit, they can facilitate external audit process, therefore if external auditors rely on internal auditors works, it is obvious that external audit costs will be reduced and delivery will be fast, this could be ideal for both clients and auditors.

Naghashiyan (1393) in his article, evaluated the influence of internal auditors performance quality on Implementation time of external audit. In this research, the day between the end of financial year and date of presenting external audit report is defined as performance time of audit. As considered time increases, information asymmetry emerges for firm financial report users, this can reduce information content in accounting reports potentially. Also, delay in presenting audit report shows the degree of audit efficiency. This research was conducted using data of 57 production firms accepted in stock exchange which provided their internal audit reports and delivered them to audit committee and board of directors. In this research needed data to test the influence of internal audit quality on external audit performance period of time were collected by questionnaire, logistic regression was used to evaluate research hypotheses. In order to examine the internal performance quality, three scales were used including objectivity, competence and audit size. Results revealed that objectivity and competence as independent variables of research, significantly influence on implementation time of external audit.

Pezeshkzade (1391) in his article "examination the reliance of external auditors on different kinds of internal audit" evaluated this subject. He suggested that increasing audit costs, results in reliance of external auditor on internal auditor in auditing financial statements. In order to coordinate increasing demand of internal audit services, many companies outscore this task to large audit institutions instead of external auditors; their aim is reducing firm costs and receiving valuable/reasonable services. Initial evaluation of external auditors according to internal auditors qualification, objectivity, work and organizational position influence on external auditors judgment about probable application of their work to adjustment, type, nature, implementation time table and limits of audit procedure.

Samavati (1379) in her research "examination the usage of analytical procedure, definition value and application of financial external audit based on small and medium institutions in Iran" concluded that maximum value of using analytical evidence based on major evidence relates to sales, sold cost and inventory. Minimum value of using analytical evidence based on complementary relates to long-term debts and other costs.

In 1985 Richard and Wills conducted a research. Some practical evidence has been collected which revealed using analytical procedures in financial audit process via provided worksheets by auditors. Results revealed that using analytical procedures have been increased since 1978-1982 and it is expected that in near future, this trend will continue. Using quality analytical procedures (mathematical) increased and using non-statistical analytical procedures decreased. Loebbecke's research results (1987) revealed that simple non-statistical procedures were not effective to justify other content tests according to them. Right and Ashton (1989) suggested that if internal controls of institutions have enough strength, analytical procedures can signal written errors in financial statements. In 1988 Coglitore et al presented no.56 audit standard for analytical procedure, although using analytical procedure results in documents showing irregularities in information, but obtained evidence by this procedure are not defendable (major evidence) in audit. Therefore using analytical procedure as major evidence, regardless to its insufficiency (originated from its intrinsic nature) can result in wrong auditor judgment. This can influence on quality of audit report. In 1988 Orton et al conducted a research "evaluation the success causes in analytical audit procedures", they proved that acceptable and sufficient examination to conclude was necessary. In this research 72 experienced auditors were selected. Results revealed that auditor reliance on acceptable evaluations accompanied with auditors judgment errors, but auditor who conducted acceptable and sufficient evaluations, and considered many factors for oscillation, their judgment errors decreased. In 2002, O'Donnell $\mathrm{ED}$ in his research 'evidence of an association between error-specific experience and auditor performance during analytical procedures" he selected some auditors with different practices to troubleshoot an unexpected change in 
an account balance. Results revealed that auditors with few experiences and error recognition capacity can explain correctly. Therefore general experiences could be replaced by error-specific experience learning.

\section{Method}

This research is descriptive-survey and in terms of goal, it is applied research.

Statistical community: Given that Iran Certificated Public Accountant (ICPA) members divided in to employed and unemployed, and only employed ones do audit activities because they are certificated, statistical community of this research is employed ones. At the time of conducting this research, number of certificated accountants were 1162 (Spring, 1394). Sample size was calculated by Cochran formula which was 351 people.in this research statistical sampling with proportional allocation was used. Identification the probable influential factors on using analytical procedure was done via study valid sources, interview with ICP, evaluation the literature, initial questionnaire, distribution to few members of ICPA.

Then, according to identified probable obstacles in initial steps of research, final questionnaire was provided and sent, finally information of received questionnaires was analyzed.

Due to this research is a kind of survey research, collecting data was done by written questionnaire. Research questionnaire was based on research goals and had different sections. Questionnaire was designed in different sections including general information and questions about 8 hypotheses. In this section, probable influential factors on using analytical procedures have been survived. Scale used for response was likert range. Scoring was as following: very high (5), high (4), medium (3), low (2), very low (1), also, very important (5), important (4), nearly important (3), less important (2), unimportant (1). In order to validate questionnaire, Coronbach alpha coefficient was used.

Statistical procedure: This research included descriptive statistics and inferential statistics. Descriptive statistics used in this research included variables and descriptive statistic like frequency, relative frequency, mean, median, standard deviation, variance, range. Inferential statistics used for examination research hypotheses was sample Wilcoxon signed-rank test.

Formula of this test is:

$$
Z=\frac{(T+0 / 5)-\mu_{T}}{\theta_{T}}
$$

In this statistic, $\mathrm{T}$ is the sum of signed rank of smaller absolute value, 0.5 is the integer factor for continuity. $\mu T$ and $\theta T$ are calculated by:

And

$$
\begin{gathered}
\mu_{T}=\frac{n(n+1)}{2} \\
\theta_{T}=\sqrt{\frac{n(n+1)(2 n+1)}{24}}
\end{gathered}
$$

Design criterion: design criterion in this research is p-value.

P-value: p-value shows the probability of confidence to $\mathrm{H} 0$ and it is an estimation of first error of hypothesis test. Therefore, in decision making, its value is compared with $5 \%$.

Making decision rule: making decision rule according to median and p-value is as following:

$$
\left\{\begin{array}{l}
H_{\circ}: \text { Median }=4 \\
H_{1}: \text { Median } \neq 4
\end{array}\right.
$$

If $\mathrm{p}$-value $\geq 0.05 \rightarrow \mathrm{AH}$

acceptance the $\mathrm{H} 0$

If $\mathrm{p}$-value $<0.05 \rightarrow \mathrm{RH}$

refusing the $\mathrm{HO}$

\section{Results and Discussion}

Initial hypothesis test: "Analytical procedures are used in external audit steps effectively".

$\mathrm{P}$-value of Wilcoxon test to examine H0:median $=4$ versus $\mathrm{H} 1:$ Median $\neq 4$ is 0.00 , which is less than $5 \%$, therefore, with confidence coefficient $=95 \%$, H0 is refused. Estimation of median value is 3.52, which is between medium and high response value. 
We examine the $\mathrm{p}$-value of Wilcoxon test for H0: Median=3 versus H0: Median $>3$. This possibility is $1.6 \%$ which is less than 5\%. Therefore, with $95 \%$ confidence coefficient,H0 is refused and the other hypothesis is accepted. Test results show that application value of analytical procedures in external audit steps is medium to high, therefore, initial hypotheses are accepted. This result is in contrast with Azizi Bozorgi's research (1375) which was done in Allame University, in this research 325 audit files were examined and using analytical procedure value were measured. Results of research mentioned above adapts with Samavati's research (1379), which was done in Tehran University. Samavati's research included this hypothesis "auditors use analytical procedures in external audit process", which was accepted by $100 \%$ confidence coefficient.

Table 1. Descriptive statistics of research variables

\begin{tabular}{|c|c|c|c|c|c|c|c|c|c|}
\hline $\begin{array}{l}\text { Number of } \\
\text { hypothesis }\end{array}$ & Research variable & $\begin{array}{c}\text { Arithmetic } \\
\text { mean }\end{array}$ & $\begin{array}{c}\text { Lower limit } \\
\text { of confidence } \\
\text { interval }\end{array}$ & $\begin{array}{l}\text { Upper limit of } \\
\text { confidence } \\
\text { interval }\end{array}$ & median & variance & $\begin{array}{l}\text { Standard } \\
\text { deviation }\end{array}$ & range & $\begin{array}{l}\text { Interquartile } \\
\quad \text { range }\end{array}$ \\
\hline Initial & External audit steps & 3.71 & 3.63 & 3.88 & 3.52 & 0.45 & 0.66 & 3 & 0.69 \\
\hline 1 & $\begin{array}{l}\text { Audit institution } \\
\text { size }\end{array}$ & 2.86 & 2.66 & 3.05 & 2.87 & 0.97 & 0.99 & 4 & 1.32 \\
\hline 2 & $\begin{array}{l}\text { Working history and } \\
\text { experiences of audit } \\
\text { manager and his } \\
\text { (her) coworkers }\end{array}$ & 3.69 & 3.56 & 3.82 & 3.77 & 0.47 & 0.66 & 3.26 & 0.65 \\
\hline 3 & $\begin{array}{l}\text { Educational level of } \\
\text { audit manager and } \\
\text { his (her) coworkers }\end{array}$ & 3.61 & 3.41 & 3.81 & 3.66 & 0.91 & 0.98 & 4 & 1.36 \\
\hline 4 & $\begin{array}{l}\text { Familiarity with } \\
\text { statistical/analytical } \\
\text { procedures }\end{array}$ & 3.47 & 3.31 & 3.62 & 3.50 & 0.65 & 0.75 & 4 & 1.01 \\
\hline 5 & Firm size & 3.96 & 3.78 & 4.13 & 4.2 & 0.78 & 0.89 & 4 & 2.3 \\
\hline 6 & Kind of industry & 3.45 & 3.20 & 3.66 & 3.58 & 0.99 & 0.98 & 4 & 0.96 \\
\hline 7 & $\begin{array}{l}\text { Accounting systems } \\
\text { and internal controls }\end{array}$ & 4.02 & 3.89 & 4.17 & 4.1 & 0.47 & 0.66 & 4 & 1 \\
\hline 8 & $\begin{array}{ll}\text { Needed initial } \\
\text { information }\end{array}$ & 4.36 & 4.13 & 4.35 & 4.27 & 0.36 & 0.59 & 2.63 & 0.82 \\
\hline
\end{tabular}

H1 test: "Audit institution size influences on using analytical procedure".

P-value of Wilcoxon test to examine H0: Median=4 versus H1: Median $\neq 4$ is 0.00 , which is less than $5 \%$, therefore with confidence coefficient $=95 \%$, $\mathrm{H} 0$ is refused. Estimation of median value is 2.875 which is between less important and nearly important. Given that median estimation is near to 3 (nearly important), we examine this hypothesis.

P-value of Wilcoxon test to examine H0: Median=3 versus H1: Median $\neq 3$ is $13.2 \%$, which is more than $5 \%$, therefore with $95 \%$ confidence coefficient, it can't be possible to refuse $\mathrm{H} 0$.

Results of test reveal that audit institution size as one of influential factors in using analytical procedures in external audit is near to nearly important, therefore $\mathrm{H} 1$ is accepted. It means that audit institution size among 8 effective factors in using analytical procedures is important (fourth priority). In other words, like partners value, personnel value, hoariness and institution contract price are less important than other factors.

H2 test: "Amount of audit manager practical experience influences on using analytical procedure".

P-value of Wilcoxon test to examine H0: Median $=4$ versus H1: Median $\neq 4$ is 0.00 , which is less than $5 \%$, therefore with $95 \%$ confidence coefficient, H0 is refused. Estimation of median value is 3.77 which is between nearly important and important response value. Also, p-value of Wilcoxon test to examine H0: Median=3 versus H1: Median $>3$ is 0.00 , which is less than $5 \%$. So, with confidence coefficient $=95 \%, \mathrm{H} 0$ is refused.

Test results show that amount of audit manager practical experiences and his (her) coworkers is near to important, therefore $\mathrm{H} 2$ is accepted. Audit manager practical experience and other professional degree is the third priority among other factors. 
Significance of practical experience of each professional degree in using analytical procedure is as following:

a) chief technical officer, b) supervisor, c) chief auditor, d) auditor.

Result of considered hypothesis is adapted to Stanly and Biggs (1984) which was conducted to evaluate how analytical examination is done by auditors. This research has proved that auditors who have few practical experience tend to use quantity (mathematical) procedures and experienced auditors tend to use judgmental procedures. Result of above hypothesis adapts to ED O Donnell (2002) which was conducted to evaluate role of error determination in one direction. In this research, it has been suggested that general experiences could be replaced by error-specific experiences.

H3 test: "Audit manager educational level influences on using analytical procedures".

P-value of Wilcoxon test to examine H0: Median $=4$ versus H1: Median $\neq 4$ is 0.00 , which is less than $5 \%$, therefore with $95 \%$ confidence coefficient, $\mathrm{H} 0$ is refused. Estimation of median value is 3.66 which is between nearly important and important response value. Also, p-value of Wilcoxon test to examine H0: Median=3 versus H1: Median $>3$ is 0.00 , which is less than $5 \%$. So, with confidence coefficient $=95 \%$, H0 is refused.

Test result reveal that audit manager educational degree and his (her) coworkers as one of influential factors on using analytical procedures in external audit is near to important, so $\mathrm{H} 3$ is accepted. Educational degree of audit manager and other professional degrees is the third priority among each educational degrees in using analytical procedures, so priorities are as following:

a) bachelor degree, b) master degree, c)doctor of philosophy.

Because for entrance to valid professional authorities in audit and accounting domain, it is necessary to have at least bachelor degree, research result adapts to mentioned necessity.

H4 test: "Familiarity with statistical-analytical methods influences on using analytical procedures".

P-value of Wilcoxon test to examine H0: Median $=4$ versus H1: Median $\neq 4$ is 0.00 , which is less than $5 \%$, therefore with $95 \%$ confidence coefficient,H0 is refused. Estimation of median value is 3.50 which is between nearly important and important response value. Also, p-value of Wilcoxon test to examine H0: Median=3 versus H1: Median $>3$ is 0.00 , which is less than $5 \%$. So, with confidence coefficient $=95 \%$, H0 is refused.

Test result shows that familiarity with statistical-analytical methods influences on using analytical procedures as one of the factors in using analytical procedure within external audit is near to important, so H4 is accepted. Result reveals that relative dominance versus complete dominance (on statistical-analytical procedures) is more important. Otherwise, it is not necessary for auditors to have complete dominance on statistical-analytical procedure and it is enough to have relative dominance.

Result of mentioned hypothesis adapts to research which was done at 1378 in Tehran Azad University by Nikpoor khokroodi.

Research of Nikpoor khokroodi included a hypothesis "lack of using statistical techniques in audit due to lack of familiarity with statistics by auditors", this hypothesis has been accepted by $95 \%$ confidence coefficient. Also, result of this hypothesis adapts to a research which was done by Azizi Bozorgi (1375) in Allame University. This research included a hypothesis" there is an association between enough recognition and using analytical audit procedure in Iran", this hypothesis has been accepted by 95\% confidence coefficient.

H5 test: "Firm size influences on using analytical procedures".

P-value of Wilcoxon test to examine H0: Median=4 versus H1: Median $\neq 4$ is 62.1 , which is higher than 5\%, therefor with $95 \%$ confidence coefficient, it is not possible to refuse H0. Estimation of median value is 4.2.

Result of test shows that firm size as a factor influencing on using analytical procedures in external audit is important, therefor H5 is accepted. Result of test reveals that total assets and total incomes of firm owners have significantly positive correlation with analytical procedures in external audit.

H6 test: "Industry influences on using analytical procedures".

P-value of Wilcoxon test to examine H0: Median $=4$ versus H1: Median $\neq 4$ is 0.00 , which is less than $5 \%$, therefor with $95 \%$ confidence coefficient, it is not possible to refuse H0. Estimation of median value is 3.58 , which is between nearly important and important response value. Also, p-value of Wilcoxon test to examine H0: Median=3 versus H1: Median $>3$ is 0.00 , which is less than $5 \%$. So, with confidence coefficient $=95 \%$, H0 is refused. Result of research reveals that industry factor as one of influential factors on using analytical procedures in external audit is near to important, therefor $\mathrm{H} 6$ is accepted. 
H7 test: "Accounting systems and efficient internal controls influence on using analytical procedures".

P-value of Wilcoxon test to examine H0: Median=4 versus H1: Median $\neq 4$ is 48.7, which is higher than 5\%, therefor with $95 \%$ confidence coefficient, it is not possible to refuse H0. Estimation of median value is 4.17. Result of research reveals that accounting systems and effective internal controls as influential factors on using analytical procedures in external audit are important, therefor H7 is accepted. Internal audit, codified accounting system, accounting management system and appropriate control environment are instances of mentioned hypothesis, result of research reveals the significance of all these factors. Result of this research adapts to Ashton and Wright(1989). Also, results of Hassas Yegane (1375) revealed that if internal control systems were strong enough, reduction of content tests and replacing analytical procedures would be less dangerous, this result adapts to $\mathrm{H} 7$ result. Above research revealed that if internal controls be strong enough, analytical procedure will signal written errors in financial statements.

H8 test: "Needed initial information like industry, budget, and standard costing influence on using analytical procedures".

P-value of Wilcoxon test to examine H0: Median $=4$ versus H1: Median $\neq 4$ is 0.00 , which is less than $5 \%$, therefor with $95 \%$ confidence coefficient, $\mathrm{H} 0$ is refused. Estimation of median value is 4.35 , which is between important and very important response value. Also, p-value of Wilcoxon test to examine H0: Median=3 versus H1: Median $>3$ is 0.00 , which is less than $5 \%$. So, with confidence coefficient $=95 \%$, H0 is refused. Significance of initial data (in questionnaire) in using analytical procedure is as following:

a) past years information, b) industry indices, c)adopted budget, d) comparable information of other firms.

Result of above research adapts to Azizi Bozorgi (1375). This research included a hypothesis "there is an association between necessity of information and using analytical audit procedures in Iran" which was accepted by 95\% confidence coefficient.

Other results: results obtained from examination the evaluation scales are as following. These information show the significance of each scale in evaluating research variables.

Table 2. Results of examination the measurement scales of research variables

\begin{tabular}{|c|c|c|c|}
\hline Title of hypothesis & Measurement scales & $\begin{array}{c}\text { Estimated } \\
\text { median }\end{array}$ & $\begin{array}{c}\text { Application } \\
\text { value/Significance level }\end{array}$ \\
\hline \multirow{3}{*}{$\begin{array}{l}\text { Analytical procedures are used effectively } \\
\text { in external audit steps }\end{array}$} & Programming step & 3 & medium \\
\hline & Content test step & 4 & high \\
\hline & Final step of audit & 4 & high \\
\hline \multirow{4}{*}{$\begin{array}{l}\text { Size of audit institution influences on using } \\
\text { influential analytical procedures }\end{array}$} & Partners & 2.5 & Near to nearly important \\
\hline & Personnel & 3 & Nearly important \\
\hline & Hoariness of institution & 3 & Nearly important \\
\hline & Contract prices & 3 & Nearly important \\
\hline \multirow{4}{*}{$\begin{array}{l}\text { Amount of audit practical experiences and } \\
\text { his(her) coworkers influence on using } \\
\text { analytical procedures }\end{array}$} & Chief technical officer & 4 & Important \\
\hline & Supervisor & 4 & Important \\
\hline & Chief auditor & 4 & Important \\
\hline & auditor & 3 & Nearly important \\
\hline \multirow{3}{*}{$\begin{array}{l}\text { Educational degree of audit manager and } \\
\text { his(her) coworkers influence on using } \\
\text { analytical procedures }\end{array}$} & Doctor of philosophy & 3.5 & Near to nearly important \\
\hline & Master degree & 4 & Important \\
\hline & Bachelor degree & 4 & Important \\
\hline \multirow{3}{*}{$\begin{array}{l}\text { Familiarity with using analytical } \\
\text { procedures influence on using analytical } \\
\text { procedures }\end{array}$} & Completely experienced & 3.5 & Near to important \\
\hline & Experienced & 3 & Nearly important \\
\hline & Nearly experienced & 4 & Important \\
\hline \multirow{2}{*}{$\begin{array}{l}\text { Firm size influences on using analytical } \\
\text { procedures }\end{array}$} & Total assets & 4 & Important \\
\hline & Total incomes of firm owners & 4 & Important \\
\hline \multirow{6}{*}{$\begin{array}{l}\text { Industry influences on using analytical } \\
\text { procedures }\end{array}$} & Food, beverage, tobacco industries & 4 & Important \\
\hline & Textile, leather industries & 4 & Important \\
\hline & Paper, paste board, publication industries & 4 & Important \\
\hline & Wood and wood craft industries & 3 & Nearly important \\
\hline & Chemical, oil, coal, rubber, plastic industries & 4 & Important \\
\hline & Minerals and non-metallic products & 4 & Important \\
\hline
\end{tabular}




\begin{tabular}{|c|c|c|c|}
\hline & Major metal production & 4 & Important \\
\hline & $\begin{array}{l}\text { Apparatus, equipment, gadgetries and metal } \\
\text { products }\end{array}$ & 4 & Important \\
\hline & Vehicles and transportation equipment & 3 & Nearly important \\
\hline & Investment firms and fiscal intermediaries & 4 & Important \\
\hline & Electrical and communicational devices & 3.5 & Near to nearly important \\
\hline \multirow{3}{*}{$\begin{array}{l}\text { Effective accounting systems and internal } \\
\text { controls influence on analytical procedures }\end{array}$} & Written and codified accounting system & 4 & Important \\
\hline & Accounting management system & 4 & Important \\
\hline & Appropriate control environment & 4 & Important \\
\hline \multirow{4}{*}{$\begin{array}{l}\text { Initial data influences on using analytical } \\
\text { procedures }\end{array}$} & Industry indices & 4 & Important \\
\hline & Adopted budget & 4 & Important \\
\hline & Past years information & 4.5 & Near to very important \\
\hline & Information of other firms with similar activities & 4 & Important \\
\hline
\end{tabular}

Many researches could be done base on this topic. Some of future topics are:

1) Evaluation the analytical procedures in accordance with each industry.

2) Doing research via observable evidence instead of questionnaire.

3) In discussed research, 8 influential factors on using analytical procedures have been confirmed, other possible factors could be topics of future researches.

\section{References}

Audit standards. Publication number 124, Audit organization, stanza 2, section 20.

Audit standards. Publication number 124, Audit organization, stanzas 2-19, section 50.

Audit standards. Publication number 124, Audit organization, stanza 3, section 52.

Azizi, B. A. (1375). A research in analytical audit procedures in Iran (Master degree thesis). Allame Tabatabaee University.

Frank, C., \& Glen, R. B. (1988). Analytical Procedures: A Defensive Necessity. Auditing: Journal of Practice \& Theory, 7(2), 150-163.

Hassas, Y. Y. (1376). Analytical procedures in audit. Quarterly Audit Evaluations, 18-19.

Loebbecke, J. K. (n. d.). An Investigation of The Use of Preliminary analytical Review to Provide Substantive Audit Evidence. Auditing: A Journal of Practice \& Theory, (11), 66-87.

Moghimi, S. M. (1380). Management office, A research trend (2nd ed.). Terme Publication.

Nemat-Allah, N. (1393). Influence of audit performance quality on performance time of external audit. Thesis, Tehran center Azad University, Accounting and Economic University.

Nezam-aidin, R., \& Hossein, G. (1392). Role and position of analytical procedures in audit (11th ed., No. 1, p. 103). Kankash publication.

NIkpoor, K. B. (1378). Evaluation the obstacles of using statistical techniques in audit process. Tehran Azad University .

O’Donnell, E. D. (2002). Evidence of an Assoiation between Error-Specific Experience and Auditor Performance During Analytical Procedures. Behavioral Research in Accounting, 14. http://dx.doi.org/10.2308/bria.2002.14.1.179

Pezeshzade, F. (1391). Evaluation the reliance of external auditors on different internal auditors. Thesis, Science Research Technology Ministry, Alzahra University, Social and Economical University.

Rezai, H. (1391). Evaluation the internal audit on external audit process. Articles of conferences in Iran, First national conference of accounting and management, Noor Azad University.

Richard, H. T., \& James, T. W. (1985). Empirical Evidence on the Changing Role of Analytical Review Procedures. Auditing: A Journal of Practice \& Theory, 4(2), 93-109.

Samavati, Z. (1379). Evaluation how using analytical procedures.... Master thesis in accounting, Tehran University. 
Sheyhk, E., Jasim, A., \& Abas, R. (1393). Role and Position of analytical procedures in audit (9th ed., n. 36. p. 9). Danesh va Pazhoohesh Publication.

Urton, A., \& Lisa, K. (1998). Evaluation the Sufficiency of Causes in Audit Analytical Procedures. Auditing: A Journal of Practice \& Theory, 17(1), 12.

Wright, A., \& Ashton, R. H. (1989). Identifying Audit Adjustments With Attention-Directing Procedures. The Accounting Review, 710-728.

\section{Copyrights}

Copyright for this article is retained by the author(s), with first publication rights granted to the journal.

This is an open-access article distributed under the terms and conditions of the Creative Commons Attribution license (http://creativecommons.org/licenses/by/3.0/). 